\title{
EGU21-6570
}

https://doi.org/10.5194/egusphere-egu21-6570

EGU General Assembly 2021

(c) Author(s) 2022. This work is distributed under

the Creative Commons Attribution 4.0 License.

\section{Active faulting offshore the Maltese Islands revealed by geophysical and geochemical observations}

\author{
Aaron Micallef ${ }^{1,2}$, Daniele Spatola ${ }^{2}$, Antonio Caracausi ${ }^{3}$, Francesco Italiano ${ }^{3}$, Giovanni Barreca ${ }^{4}$, \\ Sebastiano D'Amico ${ }^{2}$, Lorenzo Petronio ${ }^{5}$, Franco Coren ${ }^{5}$, Lorenzo Facchin ${ }^{5}$, Rita Blanos ${ }^{5}$, Alessandro \\ Pavan $^{5}$, Paolo Paganini ${ }^{5}$, Marco Taviani ${ }^{6,7,8}$, Luca Baradello ${ }^{5}$, and Emiliano Gordini ${ }^{5}$ \\ ${ }^{1}$ GEOMAR Helmholtz Centre for Ocean Research Kiel, Kiel, Germany (micallefaaron@gmail.com) \\ ${ }^{2}$ Department of Geosciences, University of Malta, Malta \\ ${ }^{3}$ Istituto Nazionale di Geofisica e Vulcanologia, Sezione di Palermo, Palermo, Italy \\ ${ }^{4}$ Dipartimento di Scienze Biologiche, Geologiche e Ambientali, Università di Catania, Catania, Italy \\ ${ }^{5}$ Istituto Nazionale di Oceanografia e di Geofisica Sperimentale (OGS), Trieste, Italy \\ ${ }^{6}$ CNR-ISMAR, Bologna, Italy \\ ${ }^{7}$ Stazione Zoologica Anton Dohrn, Napoli, Italy \\ ${ }^{8}$ Biology Department, Woods Hole Oceanographic Institution, Woods Hole, MA 02543, USA
}

The Maltese Islands (central Mediterranean Sea) are intersected by two normal fault systems associated with continental rifting to the south. Because of a lack of evidence for offshore displacement and insignificant historical seismicity, the systems have been considered to be inactive. Here we integrate aerial and marine geological, geophysical and geochemical data to demonstrate that: (i) the majority of faults offshore the Maltese Islands underwent extensional to transtensional deformation during the last $20 \mathrm{ka}$, (ii) active degassing of $\mathrm{CH}_{4}$ and $\mathrm{CO}_{2}$ occurs via these faults. The gases migrate through Miocene carbonate bedrock and the overlying PlioPleistocene sedimentary layers to generate pockmarks at the muddy seafloor and rise through the water column into the atmosphere. We infer that the offshore faults systems are permeable and that they were active recently and simultaneously. The latter can be explained by a transtensional system involving two right-stepping, right-lateral NW-SE trending faults, either binding a pull-apart basin between the islands of Malta and Gozo or associated with minor connecting antitethic structures. Such a configuration may be responsible for the generation or reactivation of faults onshore and offshore the Maltese Islands, and fits into the modern divergent strain-stress regime inferred from geodetic data. 